\title{
ANALYSIS OF THE THREE-DIMENSIONAL VECTOR FAÇADE MODEL CREATED FROM PHOTOGRAMMETRIC DATA
}

\author{
I.S. Kamnev ${ }^{1}$, V.A. Seredovich ${ }^{2}$ \\ ${ }^{1}$ Siberian State University of Geosystems and Technologies (SSUGT), 630108 Novosibirsk, Russia - kamneviv@ mail.ru \\ ${ }^{2}$ Novosibirsk State University of Architecture and Civil Engineering (Sibstrin), 630008 Novosibirsk, Russia - v.seredovich@list.ru
}

Commission V, WG V/7

KEY WORDS: terrestrial laser scanning, ground-based photogrammetry, accuracy estimation, non-metric digital cameras, threedimensional model

\begin{abstract}
:
The results of the accuracy assessment analysis for creation of a three-dimensional vector model of building façade are described. In the framework of the analysis, analytical comparison of three-dimensional vector façade models created by photogrammetric and terrestrial laser scanning data has been done. The three-dimensional model built from TLS point clouds was taken as the reference one. In the course of the experiment, the three-dimensional model to be analyzed was superimposed on the reference one, the coordinates were measured and deviations between the same model points were determined. The accuracy estimation of the threedimensional model obtained by using non-metric digital camera images was carried out. Identified façade surface areas with the maximum deviations were revealed.
\end{abstract}

\section{INTRODUCTION}

Technology modernization of cameras has led to a significant increase in the image resolution. The improvement of the digital image quality and the increase in personal computer performance make possible to use images taken by non-metric digital cameras for measuring purposes. It should be mentioned that the application of these cameras increase the efficiency of field geodetic works while making photography/surveying building façades without complex decorative elements (Jarroush, 2014, Germanak et al., 2013).

The results of accuracy assessment analysis for creation of a three-dimensional building façade vector model are described. In the framework of the analysis, an analytical comparison of three-dimensional vector façade models created by photogrammetric and terrestrial laser scanning data was done.

\section{INITIAL DATA FOR ANALYSIS}

To achieve our goal, we have made surveying of the main building of the Novosibirsk State University of Architecture and Civil Engineering using terrestrial laser scanning (TLS) and ground-based photogrammetry.

Terrestrial laser scanning technology is widely used in geospatial solutions for construction, reconstruction of buildings and structures (Ivanov, 2012, Tsakiri et al., 2006, Pu and Vosselman, 2009). It allows determining the threedimensional coordinates of the object under investigation with an accuracy of $1.5 \mathrm{~mm}$ and worse (Ivanov , 2012, Kamnev and Seredovich, 2016).

At the first stage, terrestrial laser scanning was applied for surveying of building façade from the only one scanner station. The measurements were performed by Riegl VZ-400 laser scanner during the night, cloudy and calm weather. This has made it possible to minimize the influence of refraction and vibrations of the scanner. The maximum distance from the scanner to the building façade was $30 \mathrm{~m}$.
At the second stage, ground-based photography of the façade was carried out by Sony DSC-H50 - a digital non-metric camera. It was done according to a preliminary designed work schedule, which included both route and block surveying. A special attention was paid to the necessary number of overlaps between the digital images, as well as to minimize the "dead zones". To improve the quality result of surveying, all the works were carried out during day-time and in cloudy weather at a maximum distance of $33 \mathrm{~m}$ from the camera to the façade. Totally 84 digital images were taken covering an area of 809 $\mathrm{m}^{2}$. Digital camera specification is given in Tab. 1 .

\begin{tabular}{|c|c|}
\hline Parameter & Value \\
\hline Resolution & 3459x2592 pixels \\
\hline Focus distance & $5.2 \mathrm{~mm}$ \\
\hline Aperture range & $\mathrm{f} / 2,7 \mathrm{~mm}$ \\
\hline ISO sensitivity & 80 \\
\hline Exposure & $1 / 400 \mathrm{sec}$ \\
\hline
\end{tabular}

Table 1. Specification: Sony DSC-H50 digital non-metric camera

Camera calibration was made for the further determination of camera's elements of internal orientation elements in digital image processing.

For analysis purposes, the conventional Cartesian coordinate system was adopted for a façade. In a given system, the $\mathrm{X}$-axis is directed to the zenith (towards the roof), and the $\mathrm{Y}$-axis to the east (along the building). Thus, the $\mathrm{Z}$-axis is turned perpendicular to the façade, which was considered as a height. Therefore, the building façade seems to be laid on the earth surface. A digital façade model graduated in height and in a given coordinate system is shown in Fig. 1.

To define a conditional coordinate system, 21 control points are fixed on the façade. Their coordinates are measured by a point cloud of laser reflections (scans) and assigned to the 
corresponding points on digital images. Position errors of control points on images are given in Tab. 2 .

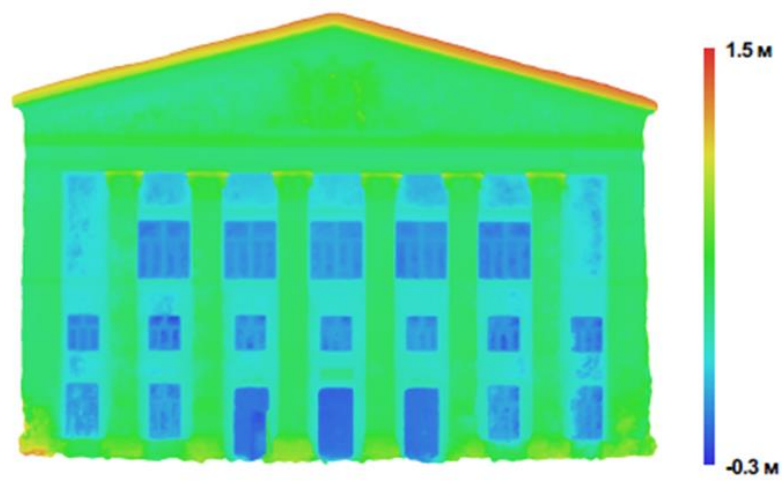

Figure 1. A digital façade model graduated in height

\begin{tabular}{|c|c|c|c|c|c|}
\hline $\begin{array}{c}\text { Point } \\
\text { ID }\end{array}$ & $\mathbf{X}[\mathbf{m}]$ & $\mathbf{Y}[\mathbf{m}]$ & $\mathbf{Z}[\mathbf{m}]$ & $\mathbf{S}[\mathbf{m}]$ & Projection \\
\hline 1 & 0.003 & 0.013 & -0.005 & 0.014 & 26 \\
\hline 2 & 0.013 & 0.014 & 0.000 & 0.030 & 19 \\
\hline 3 & 0.009 & 0.007 & 0.000 & 0.019 & 27 \\
\hline 4 & -0.003 & 0.012 & 0.005 & 0.011 & 26 \\
\hline 5 & -0.008 & -0.003 & 0.005 & 0.014 & 14 \\
\hline 6 & -0.004 & -0.011 & 0.000 & 0.010 & 20 \\
\hline 7 & 0.013 & -0.003 & -0.001 & 0.012 & 32 \\
\hline 8 & 0.007 & -0.030 & -0.006 & 0.013 & 26 \\
\hline 9 & 0.000 & -0.006 & 0.002 & 0.034 & 19 \\
\hline 10 & 0.019 & 0.004 & 0.002 & 0.007 & 22 \\
\hline 11 & 0.013 & -0.001 & 0.002 & 0.019 & 19 \\
\hline 12 & 0.008 & 0.010 & -0.003 & 0.013 & 22 \\
\hline 13 & 0.009 & 0.007 & 0.003 & 0.008 & 20 \\
\hline 14 & -0.022 & -0.005 & 0.006 & 0.013 & 19 \\
\hline 15 & -0.018 & 0.024 & -0.002 & 0.012 & 17 \\
\hline 16 & -0.005 & 0.006 & 0.001 & 0.023 & 24 \\
\hline 17 & 0.001 & -0.018 & -0.003 & 0.018 & 19 \\
\hline 18 & -0.011 & -0.007 & 0.007 & 0.015 & 23 \\
\hline 19 & -0.014 & 0.000 & -0.004 & 0.014 & 17 \\
\hline 20 & -0.006 & -0.004 & -0.002 & 0.008 & 21 \\
\hline 21 & 0.000 & -0.007 & -0.006 & 0.009 & 20 \\
\hline $\begin{array}{c}\text { RMS } \\
\text { error } \\
{[\mathbf{m}]}\end{array}$ & 0.011 & 0.012 & 0.004 & 0.016 & \\
\hline & & & & & \\
\hline
\end{tabular}

Table 2. Position errors of control points on images

According to Tab. 2, it can be seen that the root-mean-square error (RMS error) of the position of control points on $\mathrm{Z}$-axis is less than half a millimeter. The projection parameter characterizes the number of images on which a particular point is displayed. The error ' $\mathrm{S}$ ' in Tab. 2 means the RMS error of determining the spatial position of the corresponding control point.

Processing of non-metric digital camera images was carried out in the office by Agisoft PhotoScan software. As a result, a three-dimensional façade models (point and vector models) were created from point clouds and images (Fig. 2, 3).

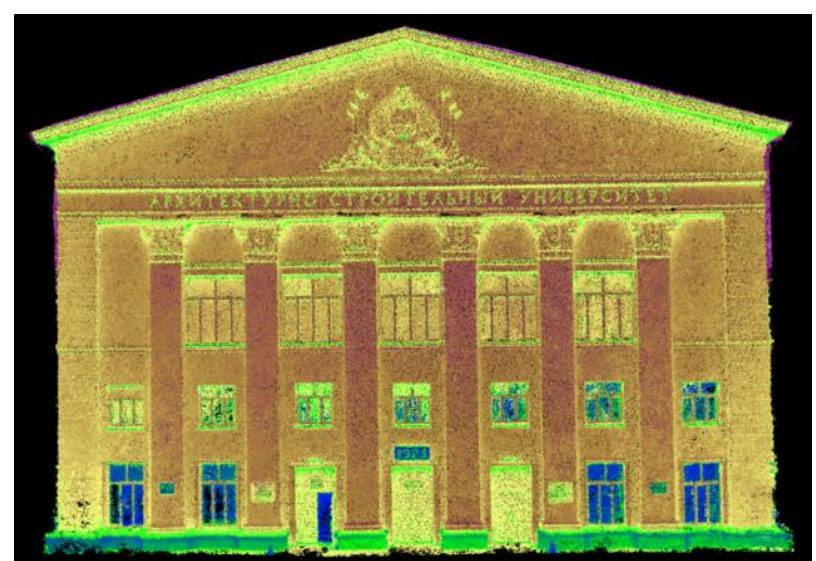

Figure 2. The three-dimensional façade model from point clouds

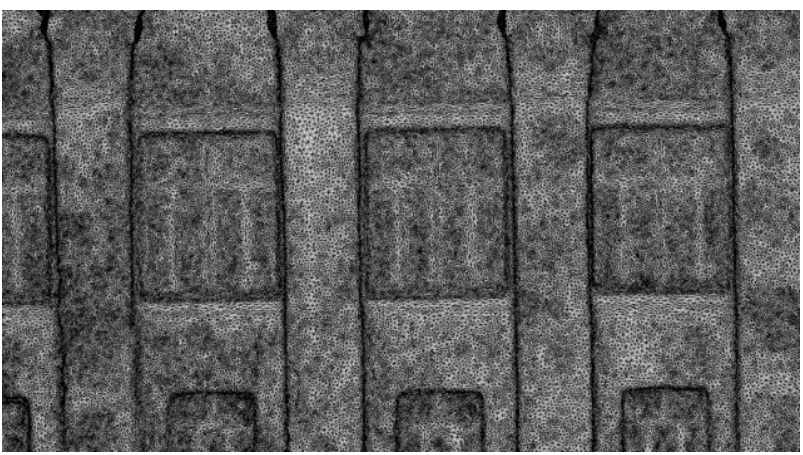

Figure 3. The three-dimensional façade model from images

As can be seen from Fig. 3, while creating a vector model from a point cloud, its edges and oblique angles are smoothed out (blurred), for example, the corners of window embrasures and the edges of columns.

The vector model was also created using TLS data (Fig. 4) and Leica Cyclone software (Fig. 5).

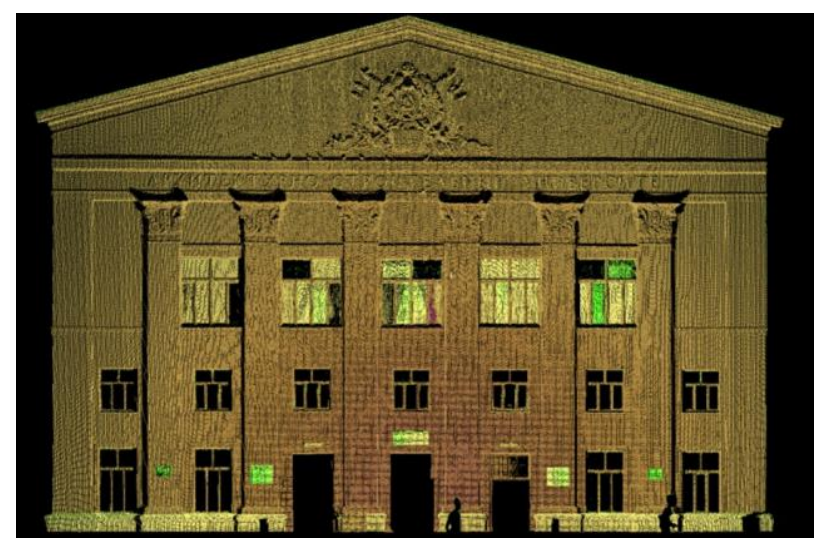

Figure 4. The three-dimensional façade model from TLS point clouds

Three-dimensional façade models from TLS point clouds shown in Fig. 2 and 4 are represented in accordance with the intensity of reflected signal.

At the next stage of data processing, the vector model from images was projected onto the TIN model created by a point 
cloud of laser reflections (scans) (Fig. 6), after which analytical comparison of data obtained was carried out.

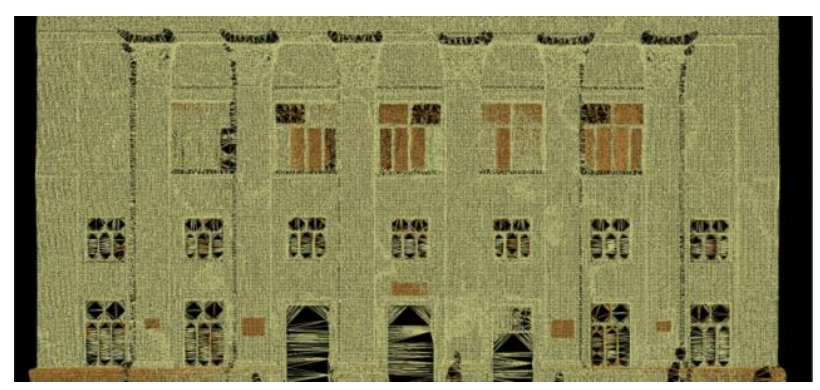

Figure 5. The three-dimensional façade model from images

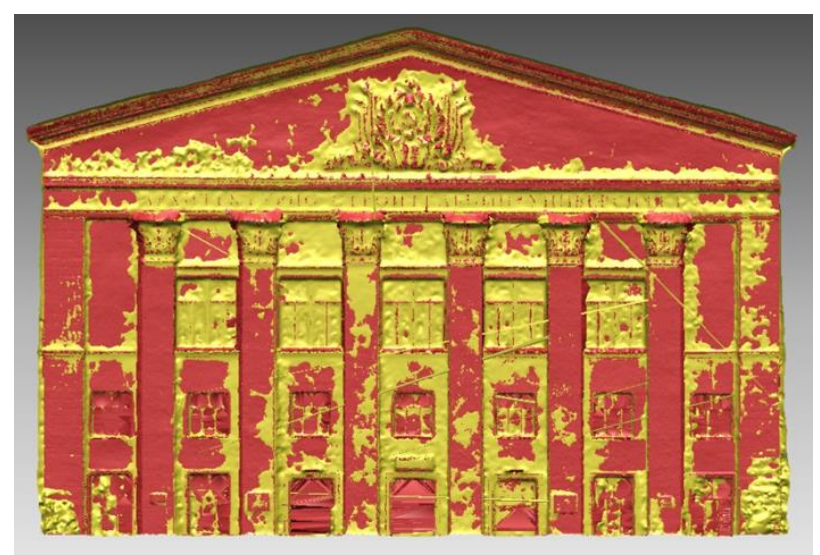

Figure 6. Fusing three-dimensional vector façade models

The three-dimensional vector model created by TLS data is shown in Fig. 6 by red colour, whereas that of created from images taken using a non-metric digital camera by yellow.

It can be seen from Fig. 6 that the greatest discrepancies between the two surfaces are in the lower model corners This could be happened due to a lack of forward overlap between images on the object edges (in this case it was 58\%), and because of a sharp turn of the wall (building edge). Significant discrepancies are also located near capitals and other relief faces, as well as in places of bending between columns, window embrasures and walls. In the upper part of the façade, deviations were appeared because of the large angle of surface inclination relative to the objective.

\section{DATA ANALYSIS}

Comparative analysis of the two models was performed manually and automatically.

The manual method consisted in uniform distribution of 101 control points across the entire building façade surface, the coordinates of which were specified theoretically (Fig. 7).

The Z-coordinates for all the control points on each model were determined, and the discrepancies between them were recorded. The data obtained are presented in Tab. 3 .

It can be seen from Tab. 3 that out of 101 measured discrepancies, only three exceed $3 \mathrm{~cm}$. The all three points are located on the relief areas of façade surface, painted with white. The maximum discrepancy between two vector models was 3.6 $\mathrm{cm}$.

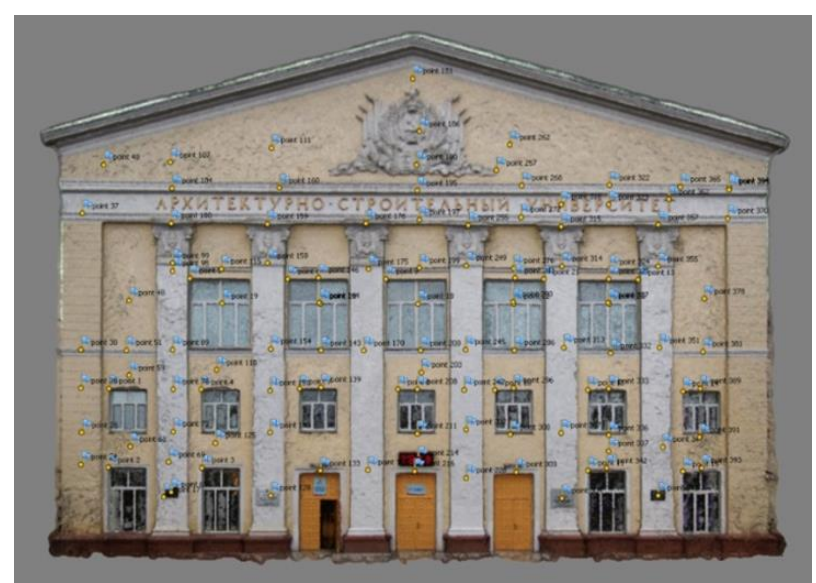

Figure 7. Point distribution across the façade

Standard formulas used for mathematical processing of geodetic measurements (Rusyaeva, 2016) were applied to determine the accuracy of three-dimensional model creation from images taken by a non-metric digital camera.

The average value is calculated by the following formula:

$$
\bar{X}=\frac{\sum_{i=1}^{n} x_{i}}{n}
$$

where

$\bar{X}=$ average value

$x_{i}=$ difference between the true value and the measured value

$n$ = number of measurements

The mean absolute deviation is calculated by the formula:

$$
M A D=\frac{\sum_{i=1}^{n}\left|x_{i}-\bar{X}\right|}{n}
$$

where

$M A D=$ mean absolute deviation

The standard error is calculated by the Gauss formula:

$$
\sigma=\sqrt{\frac{\sum_{i=1}^{n} x_{i}{ }^{2}}{n}}
$$

The results of mathematical calculations are presented in Tab. 4 .

\begin{tabular}{|c|c|c|c|}
\hline $\begin{array}{c}\text { Type of } \\
\text { surface }\end{array}$ & $\begin{array}{c}\text { Average } \\
\text { value [m] }\end{array}$ & $\begin{array}{c}\text { Mean absolute } \\
\text { deviation [m] }\end{array}$ & $\begin{array}{c}\text { Standard } \\
\text { error [m] }\end{array}$ \\
\hline Smooth & -0.003 & 0.004 & 0.006 \\
\hline Relief & -0.008 & 0.009 & 0.013 \\
\hline
\end{tabular}

Table 4. Accuracy estimation

Based on the calculations performed, it can be concluded that the measurements include a systematic error, since the modulus of the average value is close to the mean absolute deviation. That is why we have carried out an automated analysis. 


\begin{tabular}{|c|c|c|c|c|c|c|c|c|c|c|c|c|c|c|c|}
\hline \multicolumn{8}{|c|}{ Smooth surface } & \multicolumn{8}{|c|}{ Relief surface } \\
\hline № & $\mathbf{A},[\mathrm{m}]$ & $\mathbf{B},[\mathrm{m}]$ & $x_{i},[\mathbf{m}]$ & № & $\mathbf{A},[\mathbf{m}]$ & $\mathrm{B},[\mathrm{m}]$ & $x_{i},[\mathbf{m}]$ & № & $\mathrm{A},[\mathrm{m}]$ & $\mathrm{B},[\mathrm{m}]$ & $x_{i},[\mathbf{m}]$ & № & $\mathbf{A},[\mathrm{m}]$ & $\mathbf{B},[\mathrm{m}]$ & $x_{i},[\mathbf{m}]$ \\
\hline 1 & 0.448 & 0.440 & -0.008 & 30 & 0.187 & 0.187 & 0.000 & 1 & 0.476 & \begin{tabular}{|l|}
0.476 \\
\end{tabular} & 0.000 & 23 & 0.426 & 0.425 & -0.001 \\
\hline 2 & 0.442 & 0.440 & -0.002 & 31 & 0.150 & 0.151 & 0.001 & 2 & 0.465 & 0.446 & -0.019 & 24 & 0.223 & 0.217 & -0.006 \\
\hline 3 & 0.433 & 0.429 & -0.004 & 32 & 0.204 & 0.204 & 0.000 & 3 & 0.537 & 0.536 & -0.001 & 25 & \begin{tabular}{|l|}
0.172 \\
\end{tabular} & \begin{tabular}{|l|}
0.162 \\
\end{tabular} & -0.010 \\
\hline 4 & 0.363 & 0.359 & -0.004 & 33 & 0.356 & 0.365 & 0.009 & 4 & 0.217 & 0.215 & -0.002 & 26 & \begin{tabular}{|l|}
0.243 \\
\end{tabular} & \begin{tabular}{|l|}
0.240 \\
\end{tabular} & -0.003 \\
\hline 5 & 0.167 & 0.156 & -0.011 & 34 & 0.481 & 0.481 & 0.000 & 5 & 0.466 & \begin{tabular}{|l|}
0.459 \\
\end{tabular} & -0.007 & 27 & 0.205 & \begin{tabular}{|l|}
0.183 \\
\end{tabular} & -0.022 \\
\hline 6 & 0.176 & 0.164 & -0.012 & 35 & 0.478 & 0.477 & -0.001 & 6 & 0.778 & \begin{tabular}{|l|}
0.773 \\
\end{tabular} & -0.005 & 28 & \begin{tabular}{|l|}
0.229 \\
\end{tabular} & \begin{tabular}{|l|}
0.230 \\
\end{tabular} & 0.001 \\
\hline 7 & 0.173 & 0.162 & -0.011 & 36 & 0.461 & 0.456 & -0.005 & 7 & 0.547 & \begin{tabular}{|l|}
0.543 \\
\end{tabular} & -0.004 & 29 & \begin{tabular}{|l|}
0.521 \\
\end{tabular} & \begin{tabular}{|l|}
0.521 \\
\end{tabular} & 0.000 \\
\hline 8 & 0.540 & 0.541 & 0.001 & 37 & 0.456 & 0.454 & -0.002 & 8 & 0.226 & 0.226 & 0.000 & 30 & \begin{tabular}{|l|}
0.473 \\
\end{tabular} & \begin{tabular}{|l|}
0.462 \\
\end{tabular} & -0.011 \\
\hline 9 & 0.573 & 0.572 & -0.001 & 38 & 0.480 & 0.473 & -0.007 & 9 & 0.501 & \begin{tabular}{|l|}
0.478 \\
\end{tabular} & -0.023 & 31 & \begin{tabular}{|l|}
0.345 \\
\end{tabular} & \begin{tabular}{|l|}
0.344 \\
\end{tabular} & -0.001 \\
\hline 10 & 0.476 & 0.455 & -0.021 & 39 & 0.452 & 0.452 & 0.000 & 10 & 0.843 & \begin{tabular}{|l|}
0.810 \\
\end{tabular} & -0.033 & 32 & \begin{tabular}{|l|}
0.434 \\
\end{tabular} & \begin{tabular}{|l|}
0.410 \\
\end{tabular} & -0.024 \\
\hline 11 & 0.465 & 0.465 & 0.000 & 40 & 0.453 & 0.453 & 0.000 & 11 & 0.554 & 0.554 & 0.000 & 33 & \begin{tabular}{|l|}
0.573 \\
\end{tabular} & 0.572 & -0.001 \\
\hline 12 & 0.448 & 0.440 & -0.008 & 41 & 0.003 & -0.002 & -0.005 & 12 & 0.245 & \begin{tabular}{|l|}
0.242 \\
\end{tabular} & -0.003 & 34 & \begin{tabular}{|l|}
0.437 \\
\end{tabular} & \begin{tabular}{|l|}
0.405 \\
\end{tabular} & -0.032 \\
\hline 13 & 0.436 & 0.433 & -0.003 & 42 & 0.232 & 0.225 & -0.007 & 13 & 0.579 & \begin{tabular}{|l|}
0.578 \\
\end{tabular} & -0.001 & 35 & \begin{tabular}{|l|}
0.251 \\
\end{tabular} & \begin{tabular}{|l|}
0.250 \\
\end{tabular} & -0.001 \\
\hline 14 & 0.363 & 0.361 & -0.002 & 43 & 0.521 & 0.521 & 0.000 & 14 & 0.420 & \begin{tabular}{|l|}
0.420 \\
\end{tabular} & 0.000 & 36 & \begin{tabular}{|l|}
0.172 \\
\end{tabular} & \begin{tabular}{|l|}
0.163 \\
\end{tabular} & -0.009 \\
\hline 15 & 0.563 & 0.562 & -0.001 & 44 & 0.463 & 0.463 & 0.000 & 15 & 0.601 & \begin{tabular}{|l|}
0.592 \\
\end{tabular} & -0.009 & 37 & -0.005 & \begin{tabular}{|l|}
-0.016 \\
\end{tabular} & -0.011 \\
\hline 16 & 0.201 & 0.202 & 0.001 & 45 & 0.452 & 0.448 & -0.004 & 16 & 0.544 & \begin{tabular}{|l|}
0.526 \\
\end{tabular} & -0.018 & 38 & \begin{tabular}{|l|}
0.222 \\
\end{tabular} & \begin{tabular}{|l|}
0.199 \\
\end{tabular} & -0.023 \\
\hline 17 & 0.549 & 0.552 & 0.003 & 46 & 0.172 & 0.163 & -0.009 & 17 & 0.405 & 0.405 & 0.000 & 39 & \begin{tabular}{|l|}
0.273 \\
\end{tabular} & 0.272 & -0.001 \\
\hline 18 & 0.495 & 0.499 & 0.004 & 47 & 0.208 & 0.208 & 0.000 & 18 & 0.234 & \begin{tabular}{|l|}
0.234 \\
\end{tabular} & 0.000 & 40 & 0.441 & 0.419 & -0.022 \\
\hline 19 & 0.474 & 0.481 & 0.007 & 48 & 0.224 & 0.224 & 0.000 & 19 & 0.211 & 0.211 & 0.000 & 41 & 0.214 & \begin{tabular}{|l|}
0.178 \\
\end{tabular} & -0.036 \\
\hline 20 & 0.462 & 0.454 & -0.008 & 49 & 0.206 & 0.204 & -0.002 & 20 & 0.190 & \begin{tabular}{|l|}
0.198 \\
\end{tabular} & 0.008 & 42 & \begin{tabular}{|l|}
0.216 \\
\end{tabular} & 0.206 & -0.010 \\
\hline 21 & 0.447 & 0.441 & -0.006 & 50 & 0.204 & 0.204 & 0.000 & 21 & 0.803 & 0.802 & -0.001 & 43 & 0.426 & 0.420 & -0.006 \\
\hline 22 & 0.408 & 0.411 & 0.003 & 51 & \begin{tabular}{|l|}
0.509 \\
\end{tabular} & 0.510 & 0.001 & 22 & 0.558 & \begin{tabular}{|l|}
0.558 \\
\end{tabular} & 0.000 & 44 & \begin{tabular}{|l|}
0.584 \\
\end{tabular} & \begin{tabular}{|l|}
0.569 \\
\end{tabular} & -0.015 \\
\hline 23 & 0.184 & 0.183 & \begin{tabular}{|l|}
-0.001 \\
\end{tabular} & 52 & 0.473 & 0.464 & -0.009 & & & & & & & & \\
\hline 24 & 0.009 & 0.009 & 0.000 & 53 & 0.446 & 0.430 & -0.016 & & & & & & & & \\
\hline 25 & 0.195 & 0.191 & -0.004 & 54 & 0.447 & 0.447 & 0.000 & & & & & & & & \\
\hline 26 & 0.206 & 0.206 & 0.000 & 55 & \begin{tabular}{|l|}
0.167 \\
\end{tabular} & 0.158 & -0.009 & & & & & & & & \\
\hline 27 & 0.472 & 0.472 & 0.000 & 56 & 0.228 & 0.221 & -0.007 & & & & & & & & \\
\hline 28 & 0.447 & 0.447 & 0.000 & 57 & 0.208 & 0.200 & -0.008 & & & & & & & & \\
\hline 29 & 0.416 & 0.423 & 0.007 & & & & & & & & & & & & \\
\hline \multicolumn{16}{|c|}{$\begin{array}{l}\text { A - the value at a control point on the three-dimensional façade model created from TLS point clouds accepted as a true value; } \\
\text { B - the value at a control point on the three-dimensional façade vector model created from images; } \\
\qquad x_{i} \text { - the difference between the true value and the measured value }\end{array}$} \\
\hline
\end{tabular}

Table 3. Discrepancies of digital models

Automated model analysis was performed by Rapidform software. For this purpose, maps of the mean square deviations as well as absolute ones (Fig, 8-9) between the models distributed across the entire façade surface were drawn.


Figure 9. Map of the absolute deviations between threedimensional vector models

The diagram of the Gauss-Laplace distribution is shown in Fig. 10 and the map color graduation of absolute deviations between

Figure 8. Map of the mean square deviations between threethree-dimensional vector models is shown in Fig. 8. 


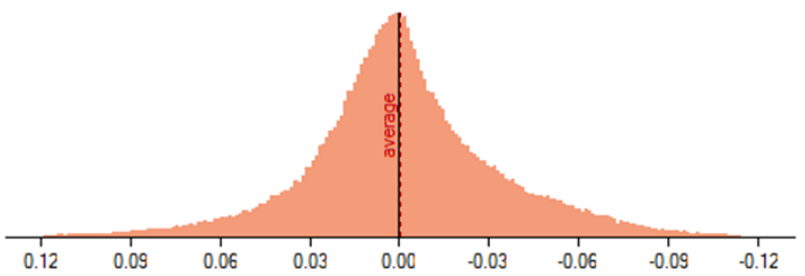

Figure 10. A diagram of the Gauss-Laplace distribution

Fig. 11 shows the diagram of absolute deviations between vector models and the map color graduation of absolute deviations displayed in Fig. 9.

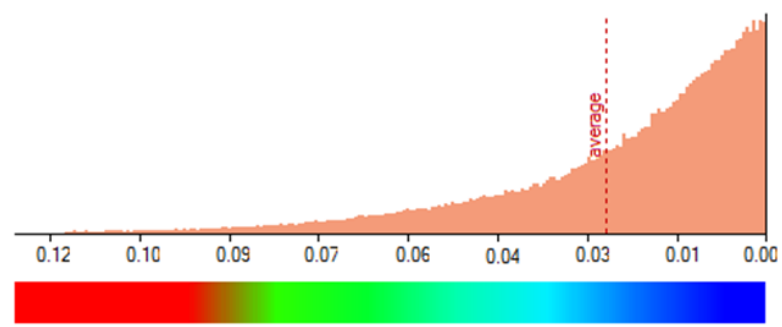

Figure 11. A diagram of the absolute deviations

The values on both diagrams are in meter.

It is evident from Fig. 9 that the deviations between vector models created have a maximum at places of surface bends because of corner smoothing.

The following data obtained from the automated analysis are presented in Tab. 5.

\begin{tabular}{|c|c|c|}
\hline $\begin{array}{c}\text { Average } \\
\text { value }[\mathbf{m}]\end{array}$ & $\begin{array}{c}\text { Mean absolute } \\
\text { deviation }[\mathbf{m}]\end{array}$ & $\begin{array}{c}\text { Standard } \\
\text { error }[\mathbf{m}]\end{array}$ \\
\hline-0.0002 & 0.027 & 0.040 \\
\hline
\end{tabular}

Table 5. Accuracy estimation

It is necessary to take into account the fact that the accuracy of three-dimensional vector model creation from images taken by a non-metric camera was calculated regarding to its comparison with that of from TLS data. In this case, the actual accuracy of photogrammetric data according to our expert analysis is as high as $10-15 \%$ because the scanning error is not equal to 0 . The results of analysis allows for the following conclusions.

\section{CONCLUSIONS}

The accuracy of the three-dimensional façade model from images taken by a non-metric camera as a whole is comparable with respect to that of the model created from TLS data. However, there are discrepancies caused by smoothing and "blurring" the object edges and sharp corners. The discrepancies also appear in case of ground-based oblique photography of objects. To eliminate these discrepancies, it is preferable to use an unmanned aerial vehicle (UAV) with a fixed camera for right angle photography. It should be mentioned that the use of non-metric digital cameras are preferable for surveying/photography of building façades which have not complex decorative elements.
The following recommendations were developed for surveying/photography of building façades and post-processing of images:

- photography should be carried out with a minimum angle (forward-backward);

- $\quad$ the frame should be with the minimum turn;

- forward and lateral overlap should be provided according to the requirements stated in the

technological documentation of Agisoft PhotoScan software;

- photography is preferable in cloudy weather;

- $\quad$ it is recommended to use a tripod providing stability for the camera.

The advantages of using non-metric digital cameras in comparison with TLS are as follows:

- low-cost equipment;

- light-weight camera for photography without a tripod. The disadvantages of photography using a digital camera are:

- longer processing time;

- $\quad$ lhe lower precision of three-dimensional models.

\section{REFERENCES}

Germanak, O. V. Kalacheva, N. A. Gugueva, O.A. Possibilities of non-metric digital cameras in ground-based photogrammetry. Engineering Journal of Don. 4 (27), pp. 205-210. (in Russian). https://elibrary.ru/item.asp?id=21452308

Ivanov, A.V. Development of methods for geodetic control of engineering facilities based on ground-based laser scanning data, PhD Thesis, Novosibirsk, 2012. - 150 p. (in Russian). http://www.dissercat.com/content/razrabotka-metodikigeodezicheskogo-kontrolya-inzhenernykh-obektov-na-osnovedannykh-nazemno

Jarroush, D. Digital camera as a surveying instrument for the needs of practice: problems and solutions. CAD and GIS of Highways. 12, pp. 52-56. (in Russian). http://www.cadgis.ru/2014/2/CADGIS-2014-1(2)11.Jarroush(Digital-camera-for-survey).pdf

Kamnev, I.S., Seredovich, V.A. Accuracy analysis of advanced measuring techniques. In Proc. of the International scientific congress "Interexpo GEO-Siberia-2016", 20-22 Apr., 2016. Novosibirsk, 2016. - Vol. 2 (2), pp. 136-141. (in Russian). https://cyberleninka.ru/article/n/issledovanie-tochnostisovremennyh-metodov-izmereniya

$\mathrm{Pu}$, S., Vosselman, G. Knowledge-based reconstruction of building models from terrestrial laser scanning data. ISPRS Journal of Photogrammetry and Remote Sensing. 64 (6), pp. 575 584 http://www.sciencedirect.com/science/article/pii/S09242716090 00501

Rusyaeva, E.A. The theory of mathematical processing of geodetic measurements. Part 1 . Theory of measurement errors. MIIGAiK, $2016 . \quad$ - 56 p. (in Russian). http://www.miigaik.ru/library/tutorials/201602261502532253.pdf

Tsakiri, M., Lichti, D., Pfeifer, N. Terrestrial Laser Scanning for Deformation Monitoring. In Proc. of 3rd IAG /12th FIG Symposium, Baden, 22-24 May, 2006, pp. 22-24. http://www.fig.net/resources/proceedings/2006/baden_2006_co mm6/PDF/LS2/Tsakiri.pdf 